\title{
Angiotensin-Converting Enzyme Inhibitor Prevents the Worsening of Renal Function in the Late Phase after Percutaneous Coronary Intervention
}

\author{
Daisuke Kanda, Takuro Takumi, Masaaki Miyata, Akihiro Tokushige, Takeshi Sonoda, Satoshi Yoshino, \\ Keishi Saihara and Mitsuru Ohishi
}

Department of Cardiovascular Medicine and Hypertension, Graduate School of Medicine and Dental Sciences, Kagoshima University, Kagoshima, Japan

\begin{abstract}
Aim: The amount of contrast media and renal atheroemboli are risk factors for acute kidney injury after percutaneous coronary intervention (PCI). However, the chronic kidney injury after PCI has not been fully characterized. The purpose of this study was to investigate factors affecting renal function in the late phase after PCI by measuring serum Cystatin $\mathrm{C}(\mathrm{Cys})$.

Methods: In 143 consecutive patients who underwent elective $\mathrm{PCI}, \mathrm{Cys} \mathrm{C}$ was evaluated at baseline and at 9 months after PCI, and the percent change in $\mathrm{CysC}(\% \mathrm{CysC})$ was calculated. The association between $\% \mathrm{CysC}$ and baseline characteristics, including medication use, was assessed.

Results: Of 143 patients, 86 had worsening renal function (WRF; \%CysC $\geq 0$ ), and 57 did not (nonWRF; \% $\mathrm{Cys} C<0$ ). Only the use of angiotensin-converting enzyme inhibitor (ACEI) and baseline CysC were significantly different between WRF and non-WRF patients $(15$ vs. $40 \%, p=0.001$ and $1.02 \pm 0.26$ vs. $1.13 \pm 0.26 \mathrm{mg} / \mathrm{L}, p=0.015)$. In univariate analysis, the use of ACEI and CysC were negatively associated with WRF [Odds ratio $(\mathrm{OR})=0.26,95 \%$ confidence interval $(\mathrm{CI})=0.12-0.57$, $p<0.001$ and $\mathrm{OR}=0.20,95 \% \mathrm{CI}=0.05-0.73, p=0.015]$. Furthermore, multivariate analysis revealed that the use of $\mathrm{ACEI}$ and $\mathrm{Cys} \mathrm{C}$ significantly correlated with WRF $(\mathrm{OR}=0.26,95 \% \mathrm{CI}=0.11-0.57$, $p<0.001$ and $\mathrm{OR}=0.20,95 \% \mathrm{CI}=0.05-0.74, p=0.016)$. The $\% \mathrm{Cys} \mathrm{C}$ in 36 patients with ACEI was significantly lower than that in 107 patients without ACEI [median: - 3.8\%; interquartile range (IQR), -11.0 to $4.2 \%$; vs. median: $3.3 \%$; IQR -2.9 to $11.0 \%, p=0.001$ ].
\end{abstract}

Conclusion: The use of ACEI was associated with lower $\mathrm{Cys} C$ after PCI, suggesting that ACEI prevents worsening of renal function in late phase after PCI.

J Atheroscler Thromb, 2016; 23: 233-240.

Key words: Cystatin C, Renal function, Angiotensin-converting enzyme inhibitor

\section{Introduction}

Percutaneous coronary intervention (PCI) is widely performed for the management of ischemic heart disease. The use of statin suppresses the progression of

Address for correspondence: Masaaki Miyata, Department of Cardiovascular Medicine and Hypertension, Graduate School of Medicine and Dental Sciences, Kagoshima University 8-35-1 Sakuragaoka, Kagoshima City, Kagoshima 890-8520, Japan

E-mail: miyatam@m3.kufm.kagoshima-u.ac.jp

Received: September 26, 2015

Accepted for publication: November 12, 2015 coronary plaques ${ }^{1)}$. Novel antiplatelet medicines are developed and have a strong antiplatelet effect in patients undergoing $\mathrm{PCI}^{2)}$. A recent study has reported that even in patients with diabetes mellitus and multivessel coronary disease, complete revascularization via PCI leads to lower long-term mortality ${ }^{3)}$. However, acute kidney injury (AKI) can occur after PCI and is associated with increased mortality ${ }^{4,5)}$. The amount of contrast media and the renal atheroemboli dislodged from the aorta by the guide catheter are major risk factors for AKI after $\mathrm{PCI}^{6,7)}$. Previous studies have demonstrated that chronic kidney disease (CKD) is an independent risk factor for cardiovascular events and 
all-cause mortality, and that CKD indicates cardiovascular events as strongly as other established risk factors ${ }^{8}$. However, the phenomenon of chronic kidney injury developing after PCI has not been fully elucidated, and factors affecting renal function in the late phase after PCI are unknown.

The serum creatinine $(\mathrm{Cr})$ concentration is commonly used for the evaluation of renal function. However, the serum $\mathrm{Cr}$ concentration is affected by several factors, such as age, gender, and body weight ${ }^{9,10)}$. Therefore, serum Cr concentration may not be accurate for the evaluation of renal function ${ }^{11)}$. Serum Cystatin $\mathrm{C}(\mathrm{Cys} \mathrm{C})$ is a new endogenous biomarker of renal function and is less influenced by age, gender, and body weight. Measurement of $\mathrm{CysC}$ can also detect AKI after PCI, and serum $\mathrm{Cys} C$ is more sensitive than the serum $\mathrm{Cr}$ in the early stage of renal dysfunction. A previous study suggested that $\mathrm{Cys} C$ is superior to serum $\mathrm{Cr}$ as a marker of renal function and is a stronger predictor of the risk of death and cardiovascular events among the elderly ${ }^{12}$. Furthermore, a recent study has reported that $\mathrm{Cys}$ C correlated with carotid intima-media thickness, which is an established maker of atherosclerosis in patients without symptoms ${ }^{13)}$.

\section{Aim}

The purpose of this study was to evaluate the change in renal function in the late phase after PCI by measuring the serum $\mathrm{Cys} C$ and to investigate factors affecting the change in renal function in the late phase.

\section{Methods}

\section{Study Population}

In this retrospective cohort study, subjects consisted of 143 consecutive patients with stable angina who underwent both elective PCI and 9-month follow-up coronary angiography at Kagoshima University Hospital from January 2010 to July 2013. The serum $\mathrm{Cys} \mathrm{C}$ was measured before PCI and at 9 months after PCI. Patients who underwent cardiogenic shock or in whom intra-aortic balloon pumping was used during PCI were excluded from this study because cardiogenic shock and the use of an intra-aortic balloon pump are risk factors for AKI. Patients treated with hemodialysis were also excluded. The institutional ethic committee of Kagoshima University Hospital approved this retrospective study. All patients provided written informed consent.

\section{PCI Procedure}

Elective PCI was performed using a standard
Table 1. Patient characteristics $(n=143)$

\begin{tabular}{lc}
\hline Age, $\mathrm{y}$ & $67 \pm 9$ \\
Body mass index, kg/m² & $24.2 \pm 3.3$ \\
Gender: men, $\mathrm{n}(\%)$ & $108(76 \%)$ \\
Contrast media, ml & $160 \pm 58$ \\
Systolic blood pressure, mm Hg & $129 \pm 18$ \\
Diastolic blood pressure, mm Hg & $73 \pm 12$ \\
Transfemoral approach, $\mathrm{n}(\%)$ & $104(73 \%)$ \\
Risk factors, $\mathrm{n}(\%)$ & \\
Hypertension & $115(80)$ \\
Dyslipidemia & $101(71)$ \\
Diabetes mellitus & $79(55)$ \\
Hyperuricemia & $44(31)$ \\
Current smoking & $3(2)$ \\
Medication, $\mathrm{n}(\%)$ & \\
Aspirin & $143(100)$ \\
Statin & $128(90)$ \\
Calcium channel blocker & $69(48)$ \\
ACEI & $36(25)$ \\
ARB & $66(46)$ \\
B-blocker & $71(50)$ \\
Spironolactone & $18(13)$ \\
Thiazide & $4(3)$ \\
Loop diuretics & $29(20)$ \\
eGF, ml/min/1.73 m ${ }^{2}$ & $65.5 \pm 17.2$ \\
G1 (>90) & $10(7)$ \\
G2 (60-89) & $76(53)$ \\
G3a (45-59) & $39(27)$ \\
G3b (30-44) & $17(12)$ \\
G4 (15-29) & $1(1)$ \\
G5 (<15) & $0(0)$ \\
\hline
\end{tabular}

Values are mean \pm SD. ACEI, Angiotensin-converting enzyme inhibitor; ARB, angiotensin II receptor blocker; eGFR, estimated glomerular filtration rate.

technique. The approach site (transfemoral or transradial) and sheath size were selected on the basis of the operator's judgement. All patients received dual antiplatelet therapy and intravenous heparin before the procedure. In patients with the serum $\mathrm{Cr}$ level greater than $1.2 \mathrm{mg} / \mathrm{dL}$, intravenous hydration with normal saline was provided at a rate of $1 \mathrm{ml} / \mathrm{kg} / \mathrm{h}$ for $12 \mathrm{~h}$ before and after PCI. A nonionic iso-osmolar contrast media was used during PCI. All patients underwent follow up coronary angiography at 9 months after PCI.

\section{Assessment of Renal Function}

Blood samples were drawn before PCI, and serum $\mathrm{Cys} C$ and $\mathrm{Cr}$ concentrations were measured. The serum $\mathrm{Cys} C$ was measured using a colloidal gold par- 
Table 2. Comparison of patient characteristics between WRF and non-WRF

\begin{tabular}{|c|c|c|c|}
\hline & $\begin{array}{l}\text { WRF } \\
(n=86)\end{array}$ & $\begin{array}{c}\text { non-WRF } \\
\quad(n=57)\end{array}$ & $P$ value \\
\hline Age, y & $67 \pm 9$ & $67 \pm 9$ & 0.619 \\
\hline Body mass index, $\mathrm{kg} / \mathrm{m}^{2}$ & $24.4 \pm 3.0$ & $23.9 \pm 3.8$ & 0.446 \\
\hline Gender: Men, n(\%) & $67(78)$ & $41(72)$ & 0.416 \\
\hline Contrast media, ml & $164 \pm 62$ & $154 \pm 50$ & 0.423 \\
\hline Systolic blood pressure, $\mathrm{mm} \mathrm{Hg}$ & $130 \pm 19$ & $126 \pm 16$ & 0.198 \\
\hline Diastolic blood pressure, $\mathrm{mm} \mathrm{Hg}$ & $74 \pm 11$ & $71 \pm 13$ & 0.070 \\
\hline Transfemoral approach, n (\%) & $66(77)$ & $38(67)$ & 0.185 \\
\hline \multicolumn{4}{|l|}{ Risk factors, n (\%) } \\
\hline Hypertension & $72(84)$ & $43(75)$ & 0.222 \\
\hline Dyslipidemia & $63(73)$ & $38(67)$ & 0.397 \\
\hline Diabetes mellitus & $47(55)$ & $32(56)$ & 0.861 \\
\hline Hyperuricemia & $28(33)$ & $16(28)$ & 0.324 \\
\hline Current smoking & $1(1)$ & $2(4)$ & 0.338 \\
\hline \multicolumn{4}{|l|}{ Medication, $\mathrm{n}(\%)$} \\
\hline Aspirin & $86(100)$ & $57(100)$ & 1.000 \\
\hline Statin & $77(90)$ & $51(89)$ & 0.962 \\
\hline Calcium channel blocker & $42(49)$ & $27(47)$ & 0.863 \\
\hline ACEI & $13(15)$ & $23(40)$ & 0.001 \\
\hline $\mathrm{ARB}$ & $44(51)$ & $22(39)$ & 0.140 \\
\hline$\beta$-blocker & $47(55)$ & $24(42)$ & 0.142 \\
\hline Spironolactone & $9(10)$ & $9(16)$ & 0.347 \\
\hline Thiazide & $2(2)$ & $2(4)$ & 0.674 \\
\hline Loop diuretics & $17(20)$ & $12(21)$ & 0.852 \\
\hline $\mathrm{Hb}, \mathrm{g} / \mathrm{dl}$ & $13.5 \pm 2.0$ & $13.2 \pm 0.4$ & 0.349 \\
\hline hs-CRP, mg /dL & $0.26 \pm 0.57$ & $0.35 \pm 1.09$ & 0.521 \\
\hline LDL-C, mg/dL & $92.7 \pm 27.0$ & $98.6 \pm 24.4$ & 0.188 \\
\hline $\mathrm{HDL}-\mathrm{C}, \mathrm{mg} / \mathrm{dL}$ & $50.4 \pm 14.7$ & $52.0 \pm 14.2$ & 0.524 \\
\hline $\mathrm{TG}, \mathrm{mg} / \mathrm{dL}$ & $131.1 \pm 68.3$ & $128.6 \pm 57.2$ & 0.827 \\
\hline $\mathrm{UA}, \mathrm{mg} / \mathrm{dL}$ & $6.1 \pm 1.3$ & $6.3 \pm 1.7$ & 0.581 \\
\hline $\mathrm{FPG}, \mathrm{mg} / \mathrm{dL}$ & $115.5 \pm 41.5$ & $114.1 \pm 43.9$ & 0.838 \\
\hline $\mathrm{HbA1c}, \%$ & $6.6 \pm 1.0$ & $6.5 \pm 1.1$ & 0.711 \\
\hline BUN, mg/dL & $18.9 \pm 6.3$ & $17.1 \pm 5.0$ & 0.065 \\
\hline $\mathrm{Cr}, \mathrm{mg} / \mathrm{dL}$ & $0.90 \pm 0.25$ & $0.89 \pm 0.25$ & 0.978 \\
\hline $\mathrm{eGFR}, \mathrm{ml} / \mathrm{min} / 1.73 \mathrm{~m}^{2}$ & $65.3 \pm 17.7$ & $65.9 \pm 16.9$ & 0.836 \\
\hline Cystatin C, mg/L & $1.02 \pm 0.26$ & $1.13 \pm 0.26$ & 0.015 \\
\hline LVEF, \% & $60.4 \pm 13.3$ & $59.9 \pm 13.4$ & 0.695 \\
\hline
\end{tabular}

Values are mean \pm SD. WRF, worsening renal function; Hb, Hemoglobin; hs-CRP, high-sensitivity C-reactive protein; LDL-C, low density lipoprotein cholesterol; HDL-C, high density lipoprotein cholesterol; TG, triglycerides; UA, uric acid, FPG, fasting plasma glucose; HbA1C, hemoglobin A1C; BNP, B-type natriuretic peptide; BUN, blood urea nitrogen; Cr, creatinine; eGFR, estimated glomerular filtration rate; LVEF, left ventricular ejection fraction.

ticle-enhanced colorimetric immunoassay (Nescauto GC Cystatin C, Alfresa Pharma, Osaka, Japan). The estimated glomerular filtration rate (eGFR) was calculated using the Modification of Diet in Renal Disease equation with coefficients modified for Japanese patients as follows: eGFR $\left(\mathrm{ml} / \mathrm{min} / 1.73 \mathrm{~m}^{2}\right)=194 \times$ serum $\mathrm{Cr}(\mathrm{mg} / \mathrm{dL})^{-1.094} \times$ age $(\text { years })^{-0.287}(\times 0.739$ for female subjects) ${ }^{14}$. The grade of renal function was classified based on the level of eGFR ${ }^{15}$. Nine months after $\mathrm{PCI}$, the serum concentrations of $\mathrm{Cys} C$ and $\mathrm{Cr}$ were reassessed. In our institution, follow-up coronary angiography is performed at 9 months after PCI, and blood test is also performed. Therefore, we evaluated the change in renal function at 9 months after PCI as 
Table 3. Logistic analysis for WRF

\begin{tabular}{|c|c|c|c|c|c|c|}
\hline & \multicolumn{3}{|c|}{ Univariate analysis } & \multicolumn{3}{|c|}{ Multivariate analysis } \\
\hline & OR & $95 \% \mathrm{CI}$ & $P$ Value & OR & $95 \% \mathrm{CI}$ & $P$ Value \\
\hline Age & 1.01 & $(0.97-1.04)$ & 0.755 & & & \\
\hline BMI & 1.04 & $(0.94-1.15)$ & 0.861 & & & \\
\hline Gender (Men) & 1.38 & $(0.63-2.98)$ & 0.418 & & & \\
\hline Contrast media & 1.00 & $(0.99-1.01)$ & 0.321 & & & \\
\hline Transfemoral approach & 1.65 & $(0.78-3.49)$ & 0.188 & & & \\
\hline Hypertension & 1.67 & $(0.73-3.87)$ & 0.225 & & & \\
\hline Dyslipidemia & 1.37 & $(0.66-2.84)$ & 0.399 & & & \\
\hline Diabetes mellitus & 0.94 & $(0.48-1.85)$ & 0.861 & & & \\
\hline Hyperuricemia & 1.15 & $(0.58-2.33)$ & 0.690 & & & \\
\hline Current smoking & 0.32 & $(0.01-3.45)$ & 0.344 & & & \\
\hline Statin & 1.01 & $(0.32-2.96)$ & 0.991 & & & \\
\hline ACEI & 0.26 & $(0.12-0.57)$ & $<0.001$ & 0.26 & $(0.11-0.57)$ & $<0.001$ \\
\hline $\mathrm{ARB}$ & 1.67 & $(0.85-3.32)$ & 0.139 & & & \\
\hline Spironolactone & 0.62 & $(0.23-1.70)$ & 0.352 & & & \\
\hline Thiazide & 0.65 & $(0.07-5.58)$ & 0.678 & & & \\
\hline Loop diuretics & 0.92 & $(0.41-2.16)$ & 0.852 & & & \\
\hline $\mathrm{Hb}$ & 1.10 & $(0.92-1.32)$ & 0.286 & & & \\
\hline hs-CRP & 0.81 & $(0.44-1.23)$ & 0.348 & & & \\
\hline $\mathrm{Cr}$ & 0.85 & $(0.22-3.28)$ & 0.812 & & & \\
\hline Cystatin C & 0.20 & $(0.05-0.73)$ & 0.015 & 0.20 & $(0.05-0.74)$ & 0.016 \\
\hline LVEF & 1.00 & $(0.97-1.02)$ & 0.800 & & & \\
\hline
\end{tabular}

Values are mean \pm SD. WRF, worsening renal function; ACEI, Angiotensin-converting enzyme inhibitor; ARB, angiotensin II receptor blocker; Hb, Hemoglobin; hs-CRP, high-sensitivity C-reactive protein; Cr, creatinine; LVEF, left ventricular ejection fraction.

the late phase. The percent change in $\mathrm{Cys} \mathrm{C}[\% \mathrm{Cys} \mathrm{C}=$ (CysC at 9 months - $\mathrm{CysC}$ at baseline)/CysC at baseline $\times 100$ ] was calculated. The recruited patients were divided into two groups depending on the \%CysC. Patients with a \%CysC of $\geq 0$ were defined as the worsening renal function (WRF) group, and the remaining patients with a \%CysC of $<0$ were defined as the non-WRF group.

\section{Statistical Analysis}

Continuous variables are expressed as mean $\pm \mathrm{SD}$. The $\chi^{2}$ test was used to compare the incidence of categorical variables. Continuous variables were compared between WRF and non-WRF groups using the Wilcoxon rank-sum test because $\mathrm{Cys} C$ data were not normally distributed. Logistic regression analysis was applied to investigate the relationship between WRF and factors. When comparing \%CysC between patients who received angiotensin-converting enzyme inhibitor (ACEI) and those that did not receive such medication, \%CysC data were expressed as median and interquartile ranges. The Kruskal-Wallis ANOVA was used to compare \% $\mathrm{Cys} C$ among three groups [e.g., those receiving ACEI, those receiving angiotensin II receptor blocker (ARB), and those receiving neither medication]. Steel-Dwass analysis was used for post hoc analysis. Statistical analyses were performed using SAS software (JMP version 11.0). A value of $p<0.05$ was considered to indicate statistical significance.

\section{Results}

\section{Baseline Characteristics}

The baseline clinical characteristics of the patients are shown in Table 1. Mean age was $67 \pm 9$ years, and $108(76 \%)$ patients were men. ACEI and ARB were prescribed for $36(25 \%)$ and $66(46 \%)$ patients, respectively, and there were no patients who were taking both ACEI and ARB. In 104 (73\%) patients, PCI was performed via the transfemoral approach. The mean volume of contrast media was $160 \pm 58 \mathrm{ml}$. The serum CysC was $1.06 \pm 0.27 \mathrm{mg} / \mathrm{L}$, and eGFR was $65.7 \pm 17.2 \mathrm{ml} / \mathrm{min} / 1.73 \mathrm{~m}^{2}$ at baseline. Seventy-six (53\%) patients had G2 renal dysfunction classified based on the level of eGFR (Table 1). 


\section{Comparison of Patients' Characteristics According to Change in Renal Function}

Eighty-six patients had worsening renal function (WRF; \%CysC $\geq 0$ ) after PCI, and 57 patients did not (non-WRF; \%CysC <0). Table 2 shows the comparison of patient characteristics between WRF and nonWRF groups. There were no significant differences in age, body mass index, gender, or the amount of contrast media between the two groups. The WRF group had a larger proportion of patients with hypertension when compared with the non-WRF group. The use of ACEI in the WRF group was lower than that in the non-WRF group (15 vs. $40 \%, p=0.001$ ). There was no significant difference in baseline serum $\mathrm{Cr}$ between the two groups. In contrast, the baseline Cys C in the WRF group was significantly lower than that in the non-WRF group $(1.02 \pm 0.26$ vs. $1.13 \pm 0.26 \mathrm{mg} / \mathrm{L}, p=$ 0.015) (Table 2).

\section{Influence of Baseline Characteristics on Change in Renal Function after PCI}

Logistic analysis was performed to investigate the association between WRF after PCI and baseline patient characteristics, including the use of medications (Table 3). In univariate analysis, the use of ACEI was negatively associated with WRF [odds ratio $(\mathrm{OR})=$ $0.26,95 \%$ confidence interval $(\mathrm{CI})=0.12-0.57, p<$ 0.001]. Baseline $\mathrm{Cys} C$ also had a negative correlation with WRF $(\mathrm{OR}=0.20,95 \% \mathrm{CI}=0.05-0.73, p=0.015)$. On the other hand, neither the baseline Cr nor the eGFR significantly correlated with WRF. Multivariate analysis revealed that both the use of ACEI and CysC independently correlated with WRF (ACEI: OR $=0.26$, $95 \% \mathrm{CI}=0.11-0.57, p<0.001$ and $\mathrm{Cys} \mathrm{C}: \mathrm{OR}=0.20$, $95 \% \mathrm{CI}=0.05-0.74, p=0.016$, respectively).

\section{Association between ACEI and Change in Renal Function}

The use of ACEI had the strongest negative correlation with WRF after PCI in multivariate analysis. Therefore, an additional analysis was performed between patients with and without ACEI. The \% CysC in 36 patients with ACEI was significantly lower than that in 107 patients without ACEI [median, - 3.8\%; interquartile range (IQR), $-11.0 \%-4.2 \%$ vs. median, $3.3 \%$; IQR $-2.9 \%-11.0 \% ; p=0.001]$ (Fig. 1). Of 107 patients who were not taking an ACEI, 66 patients were taking an $A R B$, and the remaining 41 patients were not taking either medication. \%CysC was compared among patients with ACEI $(n=36)$, with ARB $(n=66)$, and without either medication $(n=41)$; $\%$ CysC was significantly different among three groups $(p=0.013)$. $\% \mathrm{Cys} C$ in patients with ACEI was significantly lower

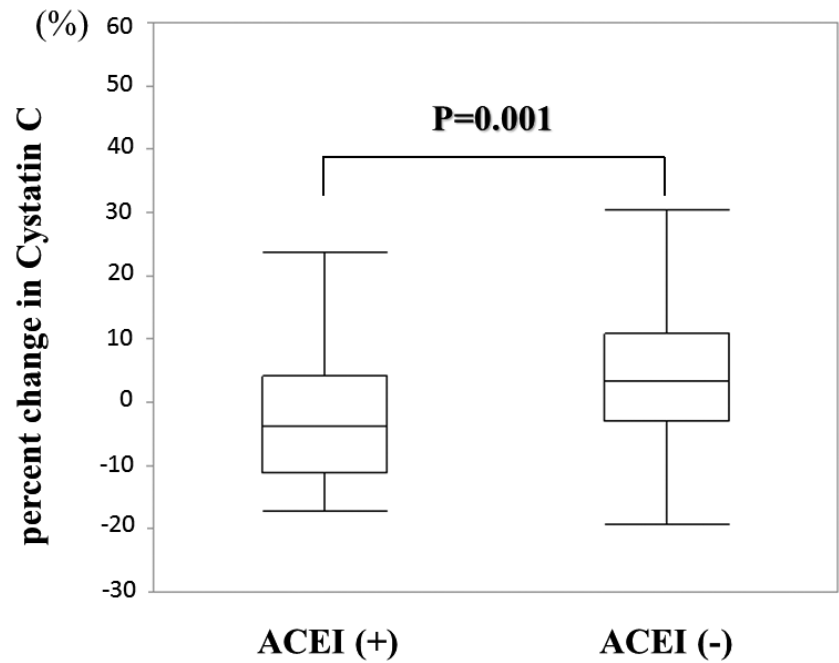

Fig. 1. Comparison of changes in Cystatin $\mathrm{C}$ between patients who were treated and not treated with an angiotensinconverting enzyme inhibitor.

The percent change in Cystatin $\mathrm{C}$ in patients with an angiotensin-converting enzyme inhibitor (ACEI) $(n=$ 36) was significantly lower than that in patients not treated with an ACEI $(n=107)$.

than that in patients with ARB or without both [ACEI $(+)$ vs. ARB (+): median, $-3.8 \%$; IQR $-11.0 \%-4.2 \%$ vs. median, $4.1 \%$; IQR $-3.3 \%-12.2 \% ; p=0.007$, and ACEI (+) vs. ACEI (-), ARB (-): median, $-3.8 \%$; IQR $-11.0 \%-4.2 \%$ vs. median: $2.5 \%$; IQR $-2.6 \%-$ $8.7 \% ; p=0.026$, respectively) (Fig. 2).

\section{Discussion}

The current study demonstrated that in patients with stable angina, baseline $\mathrm{CysC}$ and ACEI were inversely associated with a deterioration in renal function at 9 months after PCI. In comparison, baseline $\mathrm{Cr}$ and eGFR did not correlated with WRF. Furthermore, the \%CysC in patients with ACEI was significantly lower than that in patients with $A R B$ or in those who were not taking either medication, suggesting that ACEI has a protective effect against WRF in the late phase after PCI.

\section{Effect of ACEI on Renal Function after PCI}

AKI is a critical complication that can occur after PCI and is associated with increased mortality ${ }^{4,5)}$. Previous studies documented that AKI after PCI might be caused by multiple factors, including hemodynamic instability, the amount of contrast media, renal atheroemboli dislodged from the aorta by the guide catheter, and drug toxicity ${ }^{6,7)}$. It has not been determined 
whether treatment with renin-angiotensin-aldosterone system (RAAS) blockers, such as ACEI and ARB, decreases the frequency of AKI after PCI ${ }^{16,17)}$. Dangas, et al. reported that the use of ACEI might have a protective effect against AKI after PCI in patients with $\mathrm{CKD}^{5)}$. On the other hand, a few studies concluded that taking RAAS blockers is an independent risk factor for $A K I^{18,19)}$. Considering the preventive effect of ACEI on the decline in renal function in patients with $\mathrm{CKD}$ in previous long-term follow-up studies in which patients were not treated with PCI $^{20,21)}$, ACEI might contribute to the prevention of renal dysfunction in the acute phase after PCI. However, it is speculated that the hemodynamic instability, the amount of contrast media, and the occurrence of renal atheroemboli have a more powerful adverse effect on renal function when compared with the protective effect of ACEI on renal function in the acute phase after PCI.

The present study demonstrated the protective effect of ACEI on renal function in the late phase after PCI, which is consistent with the preventive effect of ACEI on renal function seen in previous studies ${ }^{20,21)}$. The renal protective effect of ACEI after PCI might be more prominent in the long-term, at a point at which the effect of hemodynamic instability, the amount of contrast media, and the occurrence of renal atheroemboli has waned.

\section{Different effects of ACEI and ARB on Renal Function}

RAAS blockers inhibit the renin-angiotensin system and have renal protective effects. These drugs are first-line agents for the treatment of $\mathrm{CKD}^{22}$. RAAS blockers expand the efferent glomerular arteriole and lead to a decrease in urine protein by reducing internal pressure of the glomerulus. As a result, these drugs might restrain the progression of renal dysfunction in the long term. Several studies reported that there were no significant differences in the prevention of renal dysfunction when comparing ACEIs and $\mathrm{ARBs}^{23,24)}$. On the other hand, although Ramipril is not available in Japan and its dose was extremely high, an ONTARGET study, which included patients with high vascular risks, demonstrated that the degree of the drop of eGFR in the ARB group was significantly bigger than that in the ACEI group at the 2-year follow-up time point ${ }^{25}$. Similarly, the current study suggested that ACEI has a stronger protective effect on renal function in the late phase after PCI when compared with that of ARB. This difference may be derived from the fact that ACEIs increase serum and tissue bradykinin levels, thereby leading to an increase in nitric oxide (NO). Previous studies demonstrated that the inhibi-

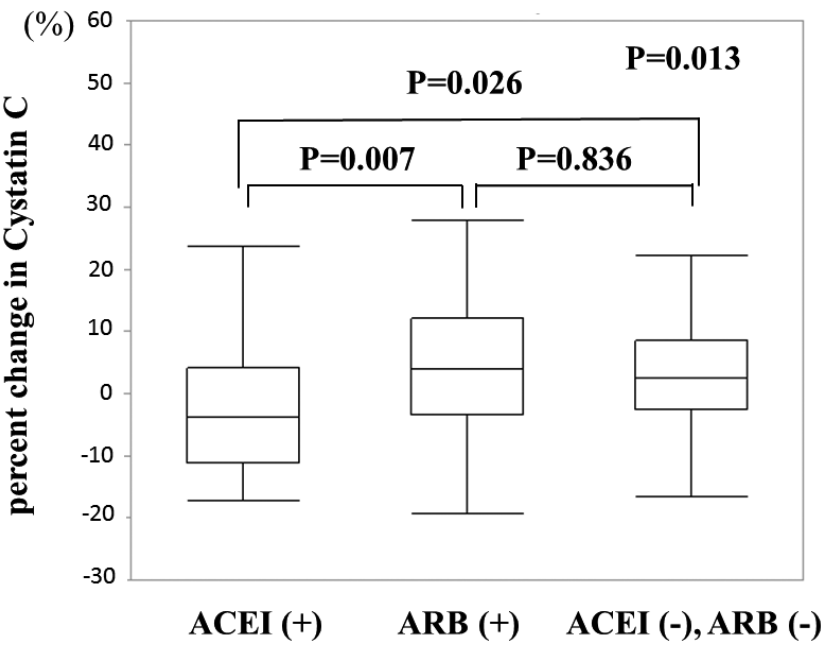

Fig. 2. Comparison of changes in Cystatin among patients who were treated with an angiotensin-converting enzyme inhibitor, an angiotensin II receptor blocker, or neither medication.

The percent change in Cystatin C (\%CysC) was significantly different among the three groups $(p=0.013)$. The \% CysC in patients treated with an angiotensinconverting enzyme inhibitor [ACEI $(+), n=36$ ] was significantly lower than that in patients treated with an angiotensin II receptor blocker [ARB (+), $n=66]$ and in those with neither medication [ACEI $(-)$, ARB $(-), n=41]$

tion of NO promotes severe and progressive arterial hypertension and renal injury ${ }^{26,27)}$ and that NO protects the glomerular filtration barrier from injury caused by superoxide ${ }^{28)}$. Another possible mechanism is that angiotensin II (Ang II) increases the expression of plasminogen activator inhibitor-1 (PAI-1) via angiotensin IV (Ang IV) ${ }^{29)}$. The expression of PAI-1 is increased in renal disease, and PAI-1 participates in the fibrosis of the kidney ${ }^{30)}$. ARB directly inhibits the binding of Ang II to Ang II type 1 receptor. Consequently, Ang II levels increase, upregulate Ang IV, and increase the expression of PAI-1. In contrast, ACEIs decrease Ang II levels by blocking angiotensin-converting enzyme.

The current study is retrospective; therefore, we could not evaluate the levels of PAI-1 via Ang IV. To confirm the above mentioned possible mechanism, further investigations are necessary to clarify the association between \%CysC and PAI-1 levels derived from ACEI or ARB by short or long time-interval observation.

\section{Measurement of CysC for the Assessment of Renal Function}

Cystatin $\mathrm{C}$ is a novel endogenous marker of renal 
function and is not affected by age, gender, body weight, or nutritional status. Several recent publications have demonstrated that $\mathrm{Cys} C$ is superior to serum $\mathrm{Cr}$ or eGFR for the assessment of renal function ${ }^{31)}$. Furthermore, several studies reported that $\mathrm{Cys} C$ is more accurate than serum $\mathrm{Cr}$ in estimating renal function, particularly in patients with mild to moderate chronic renal failure ${ }^{32,33)}$. In the present study, we estimated renal function at 9 months after PCI by measuring serum $\mathrm{CysC}$. Baseline $\mathrm{Cys} C$ is independently associated with WRF, but baseline $\mathrm{Cr}$ had no significant association with WRF. We speculate that the use of $\mathrm{Cys} C$ for renal function might result in a more accurate evaluation of renal function when compared with serum $\mathrm{Cr}$ because patients had mild to moderate renal dysfunction in our study.

Microalbuminuria also seems to be a sensitive marker for mild renal function compared with serum $\mathrm{Cr}$, and microalbuminuria might have a stronger correlation with WRF after PCI than serum CysC. However, we could not investigate this association because of the lack of data regarding microalbuminuria.

\section{Limitations}

Several limitations of this study must be considered. First, $\mathrm{Cys} C$ was measured before and at 9 months after PCI, and we demonstrated an independent association between ACEI and WRF. However, it is unknown whether ACEI has a protective effect on $\mathrm{AKI}$ after PCI because CysC was not measured in the acute phase after PCI in this study. Second, this study included patients with mild to moderate renal function. In this setting, ACEI had a protective effect on renal function at 9 months after PCI. However, the protective effect of ACEI for patients with severe renal function was not elucidated in this study. Third, this study was retrospective and contained a relatively small number of patients. Thus, we could not analyze the association between the type or the dose of ACEI and renal function after PCI. In the future, we must assess the protective effect of ACEI on renal function in a longer time-interval after PCI in a large scale prospective study. Fourth, in this study, only patients with stable angina are recruited. However, acute coronary syndrome is thought to be one of factors deteriorating renal function. Therefore, it is needed to investigate the impact of ACEI on renal function in the late phase after PCI in patients with acute coronary syndrome.

\section{Conclusion}

Use of ACEI was inversely related to the deterio- ration of renal function at 9 months after PCI. These data suggest that ACEI protects against WRF in the late phase after PCI.

\section{Conflict of Interests}

The authors declare that they have no conflicts of interest.

\section{Acknowledgements}

We thank the staff of the Department of Cardiovascular Medicine and Hypertension for their assistance with data processing.

\section{References}

1) Amemiya K, Yokoi H, Domei T, Shirai S, Ando K, Goya M, Iwabuchi M: Suppressive effects of standard-dose rosuvastatin therapy on the progression of coronary atherosclerosis in Japanese patients: the APOLLO study. J Atheroscler Thromb, 2014; 21: 1298-1307

2) Kimura T, Isshiki T, Ogawa $H$, Yokoi $H$, Yamaguchi T, Ikeda Y: Randomized, Double-Blind, Dose-Finding, Phase II Study of Prasugrel in Japanese Patients Undergoing Elective Percutaneous Coronary Intervention. J Atheroscler Thromb, 2015; 22: 557-569

3) Jiménez-Navarro MF, López-Jiménez F, Barsness G, Lennon RJ, Sandhu GS, Prasad A: Long-term prognosis of complete percutaneous coronary revascularization in patients with diabetes with multivessel disease. Heart, 2015; 101: 1233-1239

4) McCullough PA, Wolyn R, Rocher LL, Levin RN, O’Neill WW: Acute renal failure after coronary intervention: incidence, risk factors, and relationship to mortality. Am J Med, 1997; 103: 368-375

5) Rihal CS, Textor SC, Grill DE, Berger PB, Ting HH, Best PJ, Singh M, Bell MR, Barsness GW, Mathew V, Garratt KN, Holmes DR Jr: Incidence and prognostic importance of acute renal failure after percutaneous coronary intervention. Circulation, 2002; 105: 2259-2264

6) Fukumoto Y, Tsutsui H, Tsuchihashi M, Masumoto A, Takeshita A; Cholesterol Embolism Study (CHEST) Investigators: The incidence and risk factors of cholesterol embolization syndrome, a complication of cardiac catheterization: a prospective study. J Am Coll Cardiol, 2003; 42: $211-216$

7) Scolari F, Ravani P, Gaggi R, Santostefano M, Rollino C, Stabellini N, Colla L, Viola BF, Maiorca P, Venturelli C, Bonardelli S, Faggiano P, Barrett BJ: The challenge of diagnosing atheroembolic renal disease: clinical features and prognostic factors. Circulation, 2007; 116: 298-304

8) Go AS, Chertow GM, Fan D, McCulloch CE, Hsu CY: Chronic kidney disease and the risks of death, cardiovascular events, and hospitalization. N Engl J Med, 2004; 351: 1296-1305

9) Kassirer JP: Clinical evaluation of kidney function-glomerular function. N Engl J Med, 1971; 285: 385-389 
10) Levey AS: Measurement of renal function in chronic renal disease. Kidney Int, 1990; 38: 167-184

11) Perrone RD, Madias NE, Levery AS: Serum creatinine as an index of renal function: new insights into old concepts. Clin Chem, 1992; 38: 1933-1953

12) Shlipak MG, Sarnak MJ, Katz R, Fried LF, Seliger SL, Newman AB, Siscovick DS, Stehman-Breen C: Cystatin $\mathrm{C}$ and the risk of death and Cardiovascular events among elderly persons. N Engl J Med, 2005; 352: 2049-2060

13) Yamashita $H$, Nishino $T$, Obata $Y$, Nakazato $M$, Inoue $K$, Furusu A, Takamura N, Maeda T, Ozono Y, Kohno S: Association between cystatin $\mathrm{C}$ and arteriosclerosis in the absence of chronic kidney disease. J Atheroscler Thromb, 2013; 20: 548-556

14) Matsuo S, Imai E, Horio $M$, Yasuda $Y$, Tomita $K$, Nitta $K$, Yamagata K, Tomino Y, Yokoyama H, Hishida A; Collaborators developing the Japanese equation for estimated GFR: Revised equations for estimated GFR from serum creatinine in Japan. Am J kidney Dis, 2009; 53: 982-992

15) KDIGO 2012 clinical practice guideline for the evaluation and management of chronic kidney disease. Kidney Int. Suppl., 2013; 3: 1-150

16) Zhou L, Duan S: Effects of angiotensin converting enzyme inhibitors and angiotensin receptor blockers in contrastinduced nephropathy. Kidney Blood Press Res, 2013; 38: $165-171$

17) Rosenstock JL, Bruno R, Kim JK, Lubarsky L, Schaller R, Panagopoulos G, DeVita MV, Michelis MF: The effect of withdrawal of ACE inhibitors or angiotensin receptor blockers prior to coronary angiography on the incidence of contrast-induced nephropathy. Int Urol Nephrol, 2008; 40: 749-755

18) Kiski D, Stepper W, Brand E, Breithardt G, Reinecke H: Impact of renin-angiotensin-aldosterone blockade by angiotensin-converting enzyme inhibitors or AT-1 blockers on frequency of contrast medium-induced nephropathy: a post-hoc analysis from the Dialysis-versus-Diuresis (DVD) trial. Nephrol Dial Transplant, 2010; 25: 759-764

19) Umruddin Z, Moe K, Superdock K: ACE inhibitor or angiotensin II receptor blocker use is a risk factor for contrast-induced nephropathy. J Nephrol, 2012; 25: 776-781

20) The GISEN Group (Gruppo Italiano di Studi Epidemiologici in Nefrologia). Randomised placebo-controlled trial of effect of ramipril on decline in glomerular filtration rate and risk of terminal renal failure in proteinuric, nondiabetic nephropathy. Lancet, 1997; 349: 1857-1863

21) Ruggenenti P, Perna A, Gherardi G, Garini G, Zoccali C, Salvadori M, Scolari F, Schena FP, Remuzzi G: Renoprotective properties of ACE-inhibition in non-diabetic nephropathies with non-nephrotic proteinuria. Lancet, 1999; 354: 359-364

22) Zandi-Nejad K, Brenner BM: Primary and secondary pre- vention of chronic kidney disease. J Hypertens, 2005; 23: 1771-1776

23) Ferrari P, Marti HP, Pfister M, Frey FJ: Additive antiproteinuric effect of combined ACE inhibition and angiotensin II receptor blockade. J Hypertens, 2002; 20: 125-130

24) Barnett AH, Bain SC, Bouter P, Karlberg B, Madsbad S, Jervell J, Mustonen J; Diabetics Exposed to Telmisartan and Enalapril Study Group: Angiotensin-receptor blockade versus converting-enzyme inhibition in type 2 diabetes and nephropathy. N Engl J Med, 2004; 351: $1952-$ 1961

25) Mann JF, Schmieder RE, McQueen M, Dyal L, Schumacher H, Pogue J, Wang X, Maggioni A, Budaj A, Chaithiraphan S, Dickstein K, Keltai M, Metsärinne K, Oto A, Parkhomenko A, Piegas LS, Svendsen TL, Teo KK, Yusuf S; ONTARGET investigators: Renal outcomes with telmisartan, ramipril, or both, in people at high vascular risk (the ONTARGET study): a multicentre, randomised, double-blind, controlled trial. Lancet, 2008; 372: 547-553

26) Baylis C, Mitruka B, Deng A: Chronic blockade of nitric oxide synthesis in the rat produces systemic hypertension and glomerular damage. J Clin Invest, 1992; 90: 278-281

27) Ribeiro MO, Antunes E, de Nucci G, Lovisolo SM, Zatz R: Chronic inhibition of nitric oxide synthesis. A new model of arterial hypertension. Hypertension, 1992; 20: 298-303

28) Sharma M, McCarthy ET, Savin VJ, Lianos EA: Nitric oxide preserves the glomerular protein permeability barrier by antagonizing superoxide. Kidney Int, 2005; 68: 2735-2744

29) Gesualdo L, Ranieri E, Monno R, Rossiello MR, Colucci M, Semeraro N, Grandaliano G, Schena FP, Ursi M, Cerullo G: Angiotensin IV stimulates plasminogen activator inhibitor-1 expression in proximal tubular epithelial cells. Kidney Int, 1999; 56: 461-470

30) Eddy AA, Fogo AB: Plasminogen activator inhibitor-1 in chronic kidney disease: evidence and mechanisms of action. J Am Soc Nephrol, 2006; 17: 2999-3012

31) Laterza OF, Price CP, Scott MG: Cystatin C: an improved estimator of glomerular filtration rate? Clin Chem, 2002; 48: 699-707

32) Christensson AG, Grubb AO, Nilsson JA, Norrgren K, Sterner G, Sundkvist G: Serum cystatin C advantageous compared with serum creatinine in the detection of mild but not severe diabetic nephropathy. J Intern Med, 2004; 256: $510-518$

33) Artunc FH, Fischer IU, Risler T, Erley CM: Improved estimation of GFR by serum cystatin $\mathrm{C}$ in patients undergoing cardiac catheterization. Int J Cardiol, 2005; 102: 173-178 